\title{
Isolable vinylgold intermediates - first access to phantoms of homogeneous gold catalysis
}

\author{
A. Stephen K. Hashmi ${ }^{1}$ \\ www.goldbulletin.org
}

\begin{abstract}
For more than a decade vinylgold(I) compounds were written as intermediates in gold-catalysed reactions of alkynes and allenes, but only now the experimental proof for their participation in catalytic cycles could be obtained. This includes preparative access to these species, which for the first time allows to expand this aspect of organogold chemistry in new directions.
\end{abstract}

\section{Background}

In homogeneous gold catalysis, which uses welldefined soluble complexes of both gold(I) and gold(III), still the most frequently addressed functional group is the C-C triple bond in alkynes 1 (1). The alkyne is activated by the interaction with gold (complex 2) (2), backside-attack of a nucleophile $(\mathrm{Nu})$, either intramolecular or intermolecular, then delivers a vinylgold species $\mathbf{3}$. From this vinylgold intermediate $\mathbf{3}$ the gold catalyst is liberated by an electrophile (E), typically a proton (1), seldom a halogen (3) and most recently even palladium (4). During the same step the product $\mathbf{4}$ is also set free. In these reactions no experimental observation of these central vinylgold intermediates $\mathbf{3}$ was possible, the reaction with the electrophile $\mathbf{E}$ seems to be fast and no detectable concentration of $\mathbf{3}$ could accumulate. On the other hand, from our recent reactivity-studies of vinylgold compounds

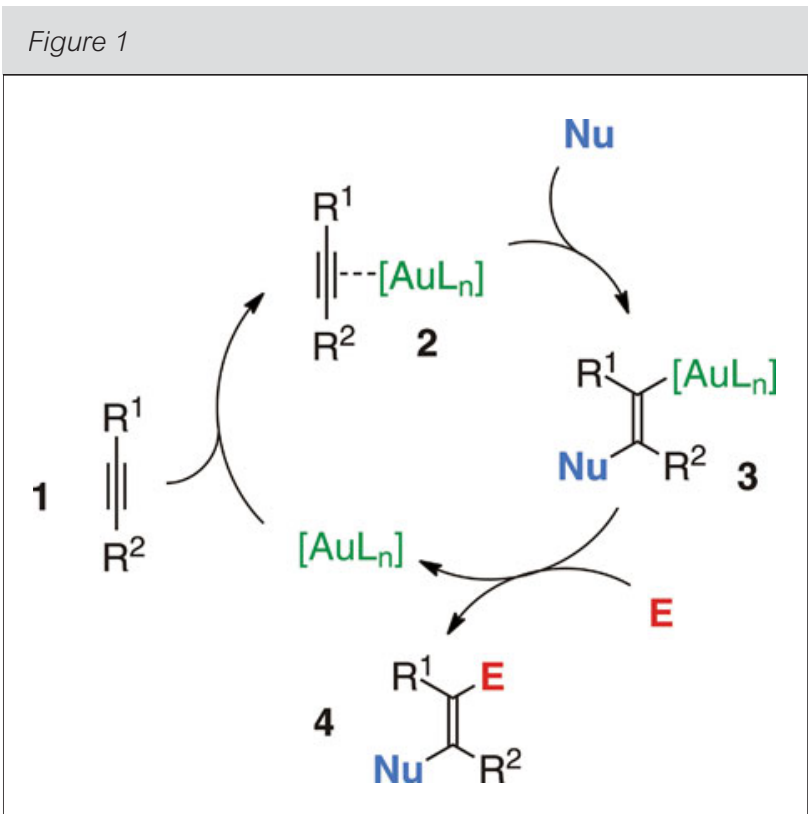

Not detected: Vinylgold intermediates as key intermediates in reactions of alkynes 1
Organisch-Chemisches Institut, Ruprecht-Karls-Universität Heidelberg, Im Neuenheimer Feld 270, D-69120 Heidelberg Germany

http://www.hashmi.de 
prepared by different routes (3d), we had learned that this class of organogold compounds should be isolable.

\section{Stable vinylgold compounds from acceptor-substituted allenes}

The first evidence for this possibility was published late last year by the group of Hammond (5). They used allenes $\mathbf{5}$ rather than the most common substrate class, the alkynes. In stoichiometric experiments with the cationic gold(I) species delivered the stable vinylgold(I) complexes $\mathbf{6}$ as shown in Figure 2. With phosphane ligands $L$ used in the investigation, the compounds $\mathbf{6}$ are thermally stable and, probably due to the acceptor group on the alkene, need $80^{\circ} \mathrm{C}$ and two equivalents of a strong Bronsted acid for protonation. Thus the compounds $\mathbf{6}$ are definitively not part of an efficient catalytic cycle (as the stability of the gold(I) catalyst at this temperature is limited and usually efficient homogeneous gold catalysis reactions often even proceed readily below room temperature) but stoichiometrically prepared organogold compounds. Still, the elemental steps of their formation, the coordination of the allene at the more electron-rich double bond in intermediate $\mathbf{A}$ and the attack of the nucleophilic carbonyl oxygen atom (shown in blue) to deliver intermediate $\mathbf{B}$, exactly resemble the single steps for the catalytic reactions of alkynes shown in Figure 1. Only the attack of the electrophilic proton (shown in red) does not occur readily, as stated above this is probably an effect of the reduced electron density in the $\mathrm{C}-\mathrm{C}$ double bond of $\mathbf{6}$, thus conveniently allowing the isolation of $\mathbf{6}$ in preparatively useful yields. Some of the compounds $\mathbf{6}$ could even

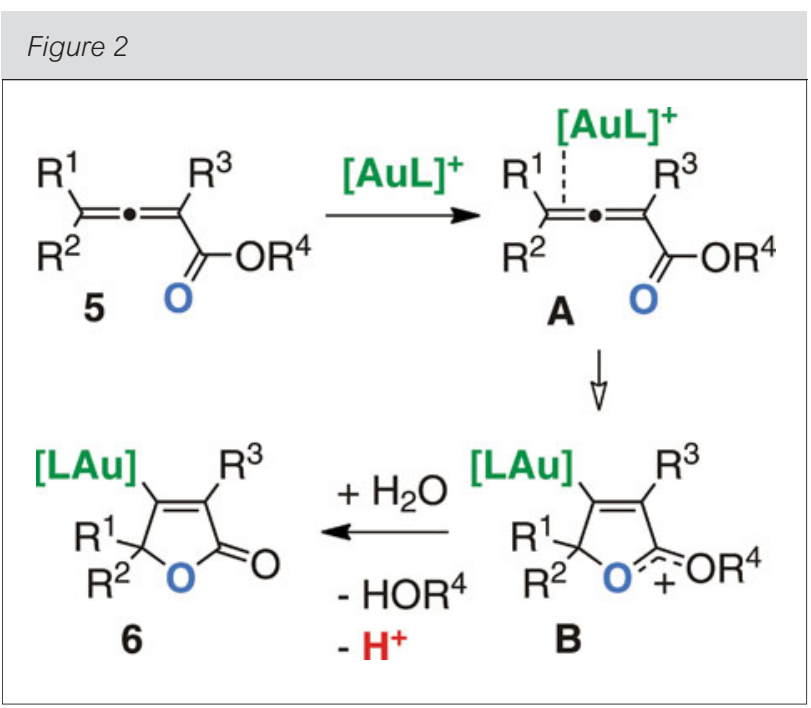

Stoichiometric: Hammond's allene-derived stable acceptor substituted vinylgold compounds $\mathbf{6}$

Figure 3

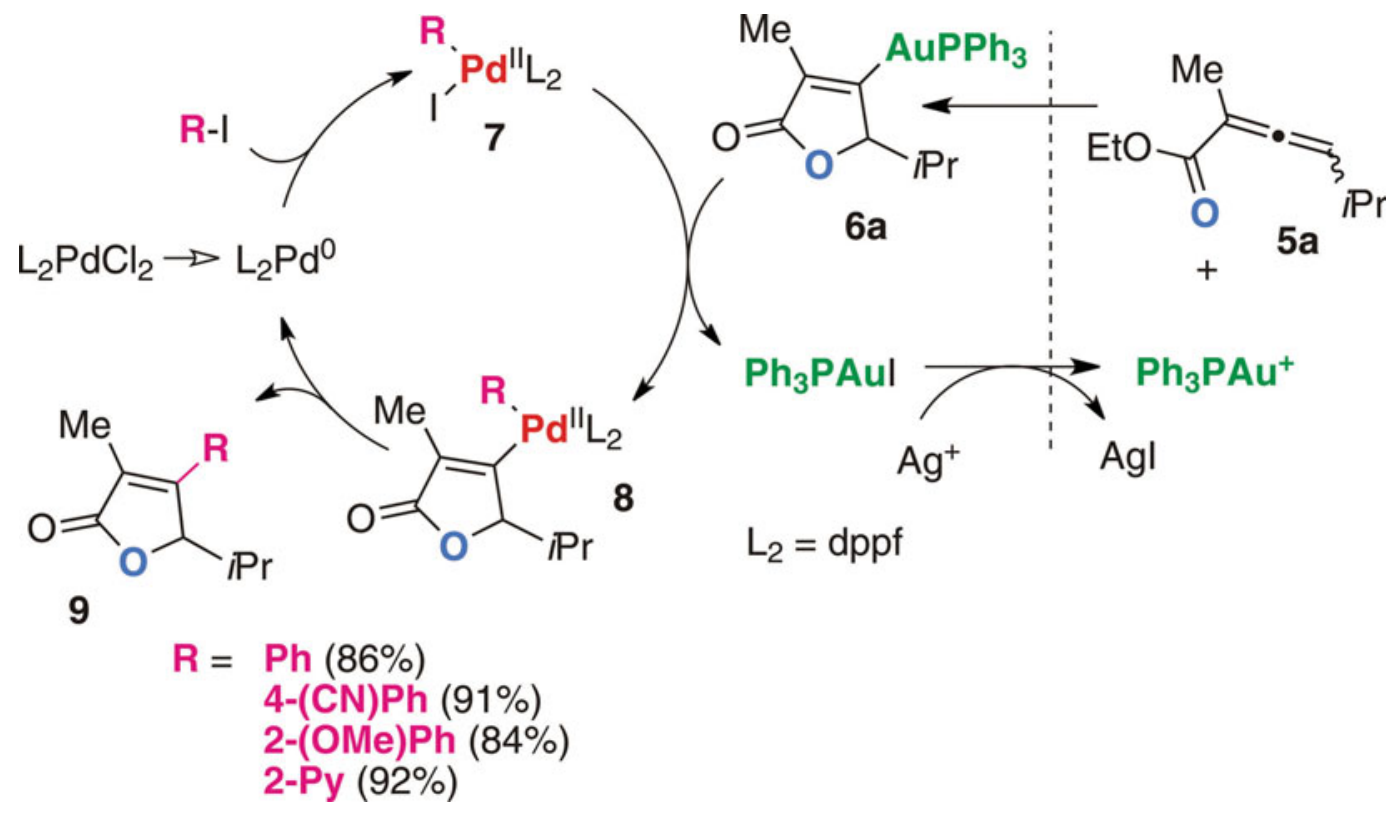

First efforts to combine a gold-catalysed cycloisomerisation with a palladium-catalysed cross coupling (dppf = 1,1'-bis(diphenylphosphino)ferrocene) 
be characterised by crystal structure analyses, ${ }^{31} \mathrm{P}$ NMR data, obtained by in situ studies, provide evidence for intermediate $\mathbf{B}$.

Furthermore, these organogold compounds can even be used in cross-coupling chemistry, this adds a new dimension to the organic chemistry of gold (4). Even exactly Hammond's vinylgold complexes could be used, Figure 3 shows the principle of these reactions, which form new C-C bonds. There is a palladium-catalyzed reaction, forming the intermediate 7 by oxidative addition of an aryl halide R-I to a palladium(0) complex with a bidentate ligand. 7 now undergoes a transmetallation reaction with the vinylgold compound $\mathbf{6 a}$ to deliver the diorganopalladium(II) species 8. In order to avoid problems with ligand exchange between the two different transition metal centers, it is best if palladium bears a bidentate ligand with a high binding constant due to the chelate effect and gold(I) bearing a monodentate ligand. 8 finally delivers the cross-coupling product $\mathbf{9}$ by reductive eliminination, which at the same time closes the catalytic cycle by re-forming palladium(0). Initially, at the begin of the catalysis, palladium( 0 ) is formed by reduction of a stable palladium(II) catalyst precursor. During the transmetallation step $\mathrm{Ph}_{3}$ PAul forms, too. It can be re-isolated in almost quantitative yield and, after removal of the iodide by $\mathrm{Ag}(\mathrm{I})$, can be re-used. In current work we try to go from such a batch-wise procedure to a process catalytic in both metals. Still, the current results are of high interest, as in synthesis they extend the scope from a simple cycloisomerisation to an extension of the carbon framework by additional C-C bond formation. The scope of the method is impressive, a number of different aryl groups $\mathrm{R}$ were successfully converted in excellent yields.

\section{Isolable vinylgold intermediates from allenes without acceptor substituent}

Soon after Hammond's results had been published, the group of Gagné was able to isolate a related vinylgold $(I)$ species 11 with phosphane ligand from intramolecular hydroarylation reactions of allenes 10 (Figure 4) (6). Again, a crystal structure analysis unambiguously confirmed the structure. Since the catalyst is also able to convert the substrate in a catalytic manner, the stability of $\mathbf{1 1}$ is limited and $\mathbf{1 1}$ is formed via an intermediate which probably bears two gold atoms, this is not a general and preparatively useful access to this class of compounds. The value of this investigation is mainly the first characterization of an allene-derived vinylgold intermediate without a stabilising acceptor substituent and the experimental evidence for intermediates with two gold atoms as potential (previously unrecognised) resting states.

\section{General route to vinylgold intermediates from alkynes}

Recent results in this field cope with alkynes as substrates, a much more frequently used class of substrates than the allenes. Furthermore, it has to be taken into account that allenes (which are thermodynamically less stable than alkynes) are more reactive than alkynes.

As shown in Figure 5, the cycloisomerisation of $N$-propargylcarboxamides 12, which in the case of terminal alkynes $\left(\mathrm{R}^{2}=\mathrm{H}\right)$ form oxazoles 13 with gold(III) catalysts (7) and alkylidene oxazolines 14 with gold(I) catalysts (8), in the case of internal alkynes $\left(R^{2}=A l k y l\right)$ the final product is not a fivemembered ring (as in 13 and 14) any more, now rather than a 5-exo-trig cyclisation, a 6-endo-dig

Figure 4<smiles>C=C=CCC(Cc1cc(OC)cc(OC)c1)(C(C)=O)C(OC)OC</smiles>

10<smiles>C=C(C1CC(C(=O)OC)(C(=O)OC)Cc2cc(OC)cc(OC)c21)C(c1ccccc1)c1ccccc1</smiles>

11

From intermediates: Gagné's vinylgold complexes without acceptor substitutent 


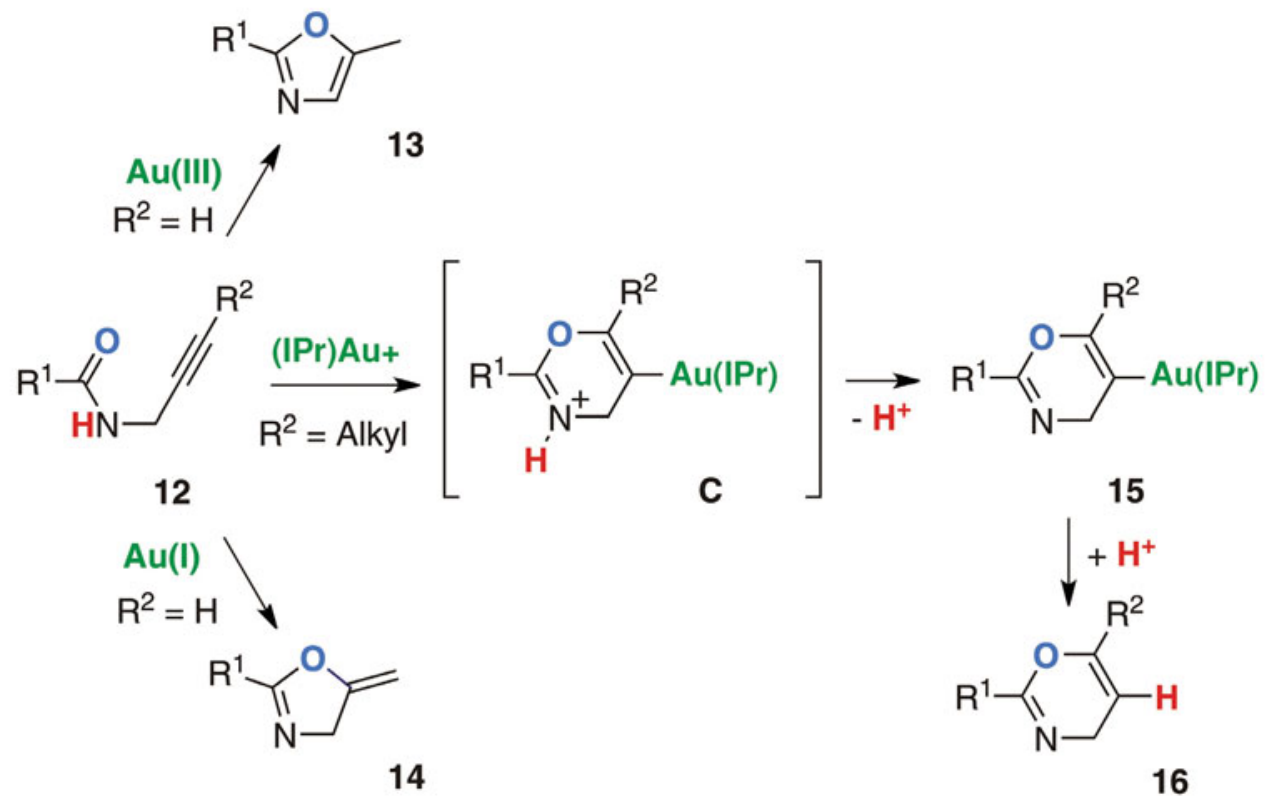

Stable intermediates and stoichiometric access: Vinylgold complexes of $\mathrm{N}$-heterocyclic ligands obtained in the presence of a base

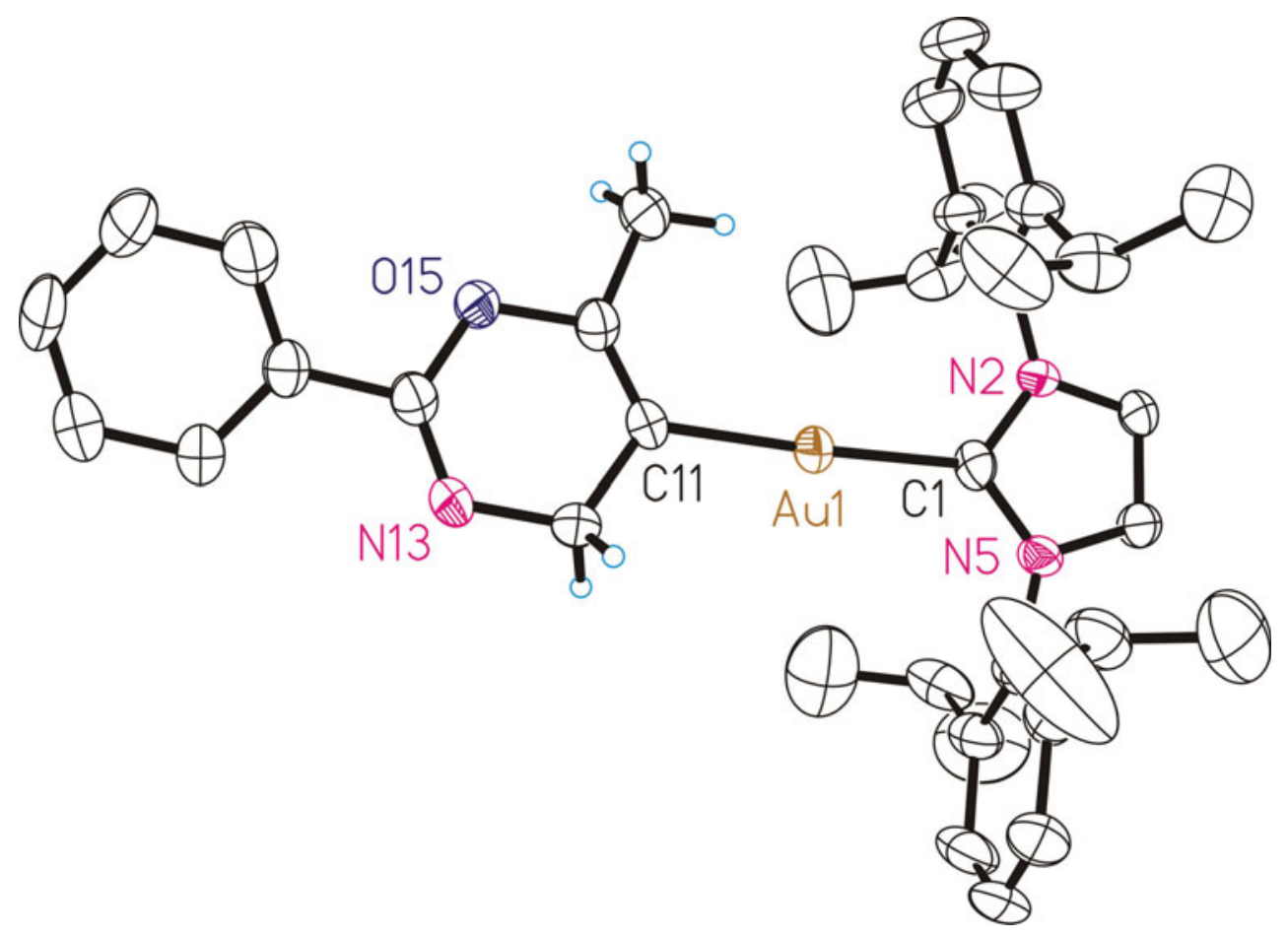

Molecular structure of a vinylgold(I) species 15. Thermal ellipsoids of the ORTEP plot shown at 50\% probability 
cyclisation ultimately delivers a six-membered ring in 16. But not only this switch in chemoselectivity is remarkable, when we used a $N$-heterocyclic carbene ligand in the presence of a simple base like triethylamine, the latter simply intercepts the electrophilic proton set free by the intermediate $\mathbf{C}$, we could isolate the vinylgold complexes $\mathbf{1 5}$ in very good yields on preparative scale (9). The fact that 15 really is an isolable intermediate of the catalytic cycle is supported by the observation that both 15 alone and $\mathbf{1 5}$ in the presence of acid still catalyse the transformation of $\mathbf{1 2}$. This procedure should be of general scope and applicable to most related gold-catalysed conversions of alkynes.

The structure of one derivative $15\left(R^{1}=P h, R^{2}=M e\right)$ was proven by a X-ray crystal structure analysis. A picture is shown in Figure 6. In this structure it is interesting to note that both gold-carbon distances, the one to the vinyl carbon and the one to the carbon atom of the $\mathrm{N}$-heterocyclic carbene, are almost identical.

\section{Conclusions}

Recent publications, all from the last 10 months, document a large step forward in the understanding, characterization and detection of key intermediates of gold catalysed homogeneous reactions, the vinylgold(I) species. These papers have shown how these elusive intermediates can be stabilised by acceptors on the substrate, the presence of a base and the use of $\mathrm{N}$-heterocyclic carbenes as ligands for gold. All these quite new findings will help to add a new dimension to homogeneous gold catalysis.

\section{Acknowledgements}

We are very grateful for funding by the Deutsche Forschungsgemeinschaft DFG and donations of gold salts by Umicore AG \& Co KG.

\section{About the author}

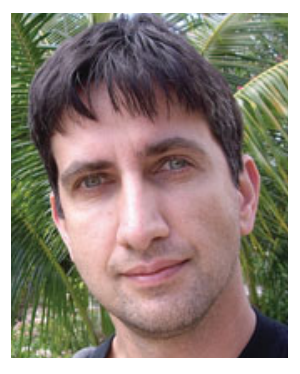

A. Stephen K. Hashmi occupies a chair of organic chemistry at Ruprecht-Karls-Universität Heidelberg. He carried out his Diploma and PhD research with Professor G. Szeimies at the Ludwig-Maximilians-Universität München in the field of strained organic compounds such as allenes, bicyclobutanes and propellanes.
His postdoctorate research with Professor B. M. Trost at Stanford University, California, covered transition metal catalysed reactions involving enyne metathesis. His habilitation with Prof. J. Mulzer at the Freie Universität Berlin, the Johann Wolfgang Goethe-Universität Frankfurt and the Universität Wien, Austria, as well as visits at the University of Tasmania, Australia, the Universität Marburg and a professorship at the Universität Stuttgart focused on both stoichiometric organometallic chemistry and transition metal catalysed organic reactions. Today, homogeneous gold-catalysed organic reactions are the major topic in the group.

\section{References}

1 (a) A.S.K. Hashmi, Gold Bull., 2003, 36, 3. (b) A.S.K. Hashmi, Gold Bull., 2004, 37, 51; (c) A.S.K. Hashmi, G.J. Hutchings, Angew. Chem., 2006, 118, 8064; Angew. Chem. Int. Ed., 2006, 45, 7896; (d) A. Fürstner, P.W. Davis, Angew. Chem., 119, 3478; Angew. Chem. Int. Ed., 2007, 46, 3410; (e) D.J. Gorin, F.D. Toste, Nature 2007, 446, 395; (f) A.S.K. Hashmi, Chem. Rev., 2007, 107, 3180; (g) A. Arcadi, Chem. Rev., 2008, 108, 3266; (h) E. Jiménez-Núnez, A.M. Echavarren, Chem. Rev., 2008, 108, 3326; (i) Z.G. Li, C. Brouwer, C. He, Chem. Rev., 2008, 108, 3239

2 M. Pernpointner, A.S.K. Hashmi, J. Chem. Theory Comput., 2009, 5, 2717

3 (a) A. Buzas, F. Gagosz, Org. Lett., 2006, 8, 515. (b) S.F. Kirsch, Angew. Chem., Int. Ed., 2007, 46, 2310. (c) L. Zhang, Org. Lett., 2007, 9, 2147. (d) A.S.K. Hashmi, T.D. Ramamurthi, F. Rominger, J. Organomet. Chem., 2009, 694, 592

4 A.S.K. Hashmi, C. Lothschütz, R. Döpp, M. Rudolph, T.D. Ramamurthi, F. Rominger, Angew. Chem., 2009, 121, 8392; Angew. Chem. Int. Ed., 2009, 48, 8243

5 L.-P. Liu, B. Xu, M.S. Mashuta, G.B. Hammond, J. Am. Chem. Soc., 2008, 130, 17642

6 D. Weber, M.A. Tarselli, M.R. Gagné, Angew. Chem., 2009, 121, 5843; Angew. Chem., Int. Ed., 2009, 48, 5733

7 A.S.K. Hashmi, J.P. Weyrauch, W. Frey, J.W. Bats, Org. Lett., 2004, 6, 4391

8 J.W. Weyrauch, A.S.K. Hashmi, A. Schuster, T. Hengst, S. Schetter, A. Littmann, M. Rudolph, M. Hamzic, J. Visus, F. Rominger, W. Frey, J.W. Bats, Chem. Eur. J., 2009, 15, in press

9 A.S.K. Hashmi, A. Schuster, F. Rominger, Angew. Chem., 2009, 121, 8396; Angew. Chem. Int. Ed., 2009, 48, 8247 